\title{
Phonemic-analysis training helps children benefit from spelling-sound rules
}

\author{
REBECCA TREIMAN \\ Indiana University, Bloomington, Indiana \\ and \\ JONATHAN BARON \\ University of Pennsylvania, Philadelphia, Pennsylvania
}

\begin{abstract}
It has been frequently suggested that the ability to analyze spoken words into phonemes facilitates children's learning of spelling-sound rules. This research attempts to demonstrate that link by showing that phonemic-analysis training helps children take advantage of spellingsound rules in learning to read. In two experiments, preschool and kindergarten prereaders participated in an analysis condition and a control condition on each of 4 test days. In the analysis condition, children learned to segment (and in Experiment 2, also to blend) selected spoken syllables. In the control condition, they merely repeated syllables. Children were then introduced to printed items that corresponded to the spoken syllables with which they had worked. The pronunciation of the "related" item could be deduced from those of other printed items in the set; the pronunciation of the "unrelated" item could not be so deduced. Both experiments revealed a significant interaction between condition (analysis vs. control) and item type (related vs. unrelated). In the control condition, children tended to make more errors on the related item than on the unrelated item; in the analysis condition, they tended to make fewer errors on the related item than on the unrelated item. These results suggest a causal link between the ability to analyze spoken syllables and the ability to benefit from spelling-sound relations in reading.
\end{abstract}

It is important for young readers to learn the rules that relate spellings to sounds. Children who are able to use these rules, dubbed "Phoenicians" (Baron, 1979), can often decode printed words that they have never seen before. Children who are less able to use spelling-sound rules, or "Chinese," are forced to rely on word-specific associations-memorized associations between individual printed words and their pronunciations and/or meanings. Readers who depend on such associations should have difficulty as the size of their written vocabulary increases and as new words must be deciphered (Rozin \& Gleitman, 1977). Empirical evidence supports the view that "Phoenicians" tend to be better readers of an alphabetic writing system than are "Chinese." Firth (1972),

We thank Ann Farrell, Shellie Haut-Rogers, Ivy Kuhn, Sharon Packer, and Becky Taggart for their assistance in various phases of this research. Kathy Hirsh-Pasek, David Pisoni, and Linda Smith gave valuable comments on earlier drafts of the manuscript. This research was supported by NIH Grant MH-29453 to J.B., Grant BRSG S07 RR07031 to R.T., and NSF Grant BNS 81-09892 to R.T. Portions of these data were presented at the meeting of the Society for Research in Child Development, Boston, April 1981. R. Treiman's mailing address is: Department of Psychology, Indiana University, Bloomington, Indiana 47405; J. Baron's mailing address is: Department of Psychology, University of Pennsylvania, Philadelphia, Pennsylvania 19104. for example, found that the ability to pronounce nonsense words accounted for about $75 \%$ of the variance in reading ability among a group of 916 -yearolds. Furthermore, children with specific difficulties in learning to read, or dyslexics, are generally poor at using spelling-sound rules (Boder, 1971, 1973; Snowling, 1980).

Given that spelling-sound rules play a central role in learning to read, as the above studies indicate, it is important to understand why some children have difficulty learning these rules. One contributing factor may be their lack of phonemic-analysis ability. In alphabetic languages such as English, written letters typically represent phonemes. ${ }^{1}$ Many investigators have argued that children have trouble learning the correspondences between letters and phonemes because they lack access to a phonemic representation of speech (Elkonin, 1973; Gleitman \& Rozin, 1977; Golinkoff, 1978; Liberman, Liberman, Mattingly, \& Shankweiler, 1980; Rozin \& Gleitman, 1977; Treiman \& Baron, 1981; Wallach \& Wallach, 1979). Indeed, various studies indicate that children who have not yet learned to read, or children who are just starting to read, are poor in phonemic analysis. For example, such children often fail to produce or appreciate rhymes (e.g., Calfee, Chapman, \& Venezky, 1972). They have difficulty in judging the number of 
phonemes in a spoken word (e.g., Liberman, Shankweiler, Fischer, \& Carter, 1974; Treiman \& Baron, 1981), and they do poorly in segmentation and blending tests that require them to pronounce the separate phonemes in a word or to recognize a word when they are given a string of phonemes (e.g., Fox \& Routh, 1975; Hardy, Stennett, \& Smythe, 1973).

Consistent with the view that phonemic analysis is critical in the acquisition of spelling-sound rules, which are important for reading success, measures of phonemic-analysis ability correlate with scores on standard reading tests (e.g., Calfee et al., 1972; Calfee, Lindamood, \& Lindamood, 1973; Firth, 1972; Fox \& Routh, 1975; Helfgott, 1976; Jusczyk, 1977; Rosner \& Simon, 1971). Furthermore, phonemic analysis correlates more highly with ability to use spellingsound rules than with ability to use word-specific associations (Baron \& Treiman, 1980; Treiman \& Baron, 1981). That is, Phoenician-style readers exceed Chinese-style readers in phonemic awareness. However, none of the above studies conclusively demonstrated a direct causal link from phonemic awareness to the learning of rules. Indeed, some evidence suggests a link in the reverse direction. That is, people may do well on phonemic-analysis tests precisely because they know how to read (Baron \& Treiman, 1980; Ehri \& Wilce, 1979; Morais, Cary, Alegria, \& Bertelson, 1979). It is at least possible that this reverse causal link-phonemic analysis as a result of learning to read-could explain the entire correlation between phonemic analysis and spellingsound-rule use.

To find out if a causal link exists from phonemicanalysis ability to ability to learn spelling-sound rules, other experimental approaches are necessary. One approach is to train prereaders in phonemic analysis and to determine whether this training improves their learning of spelling-sound rules. In one study using this approach, Rosner (Note 1) divided 16 first-graders who were not yet able to read into two groups. Children in the experimental group were trained for 14 weeks in the analysis of spoken words into syllables and phonemes. Children in the control group received no special instruction. On a subsequent reading test, the trained children outscored the untrained children by a substantial margin. These results are promising, but there are two reasons why they fail to conclusively show a link from phonemic analysis to spelling-sound-rule acquisition. One reason stems from the use of a between-groups design. The extra attention given the experimental group may have had general effects (e.g., increased motivation or confidence) that in turn caused the superior reading performance. The second problem is that the reading test did not distinguish use of spellingsound rules from use of word-specific associations. By hypothesis, phonemic-analysis training should specifically affect the learning of spelling-sound rules.

A study by McNeil and Coleman (Note 2) partially solved these problems by using two control groups. The experimental group of 30 kindergarteners (Group E) received 3 weeks of phonemic-analysis training followed by 3 weeks of reading instruction. One control group of 30 children (Group C1) received the 3-week reading program twice in succession, for a total of 6 weeks of instruction. A second control group of 30 children (Group C2) did the reading program once. On a final reading test, Group $\mathrm{E}$ performed significantly better than did Groups $\mathrm{Cl}$ and $\mathrm{C} 2$. The superiority of Group E over Group C1 could not have been due to the time devoted to special training-the two groups were equal in this regard. However, the children in Group $\mathrm{C} 1$, who did the identical reading program twice, may have suffered adverse motivational effects due to the repetition and lack of variety in their reading instruction. Clearly, more converging evidence is needed to conclude strongly that phonemic-analysis training affects the learning of spelling-sound rules rather than (or to a greater degree than) some other readingrelated skill.

The purpose of the present experiments was to provide additional evidence on phonemic-analysis training and the learning of spelling-sound rules. These experiments differed from those of Rosner (Note 1) and $\mathrm{McNeil}$ and Coleman (Note 2) in two ways. First, the training manipulations were carried out within subjects. Each child received phonemic analysis instruction with certain sets of spoken syllables and no such instruction with other sets of syllables. Second, the reading tasks were specifically designed to measure children's use of spelling-sound rules. Transfer of spelling-sound rules from one word to another served as the index of rule use. ${ }^{2}$ Such transfer is, for educational purposes, the best measure of children's use of spelling-sound rules. We are satisfied that children have learned rules when they can transfer them to novel items-when they can decode new words on the basis of previously learned words. We predicted that children would be more likely to transfer spelling-sound rules when they read novel words whose spoken forms they had been trained to analyze than when they read novel words whose spoken forms they had not been trained to analyze.

\section{EXPERIMENT 1}

Prereaders participated individually in Experiment 1 on 4 different days. Each day, they took part in an analysis condition and then a control condition. In the first phase of each condition, the children worked only with spoken syllables. In the analysis condition, they learned to segment four syllables into their initial consonants and remaining portions. For example, the four syllables might be "hem," "lig," 
"hig," and "lem." The children learned to respond "h," "em" to "hem," "l," "ig" to "lig," and so on, continuing until they had reached a criterion. In the control condition, the children were exposed to four different syllables (for example "diz," "vok," "dok," "viz") but were not taught to segment them. Instead, they simply repeated the syllables aloud for the same number of trials as in the immediately preceding analysis condition.

The second phase of each condition involved a reading task. The nature of the task was the same in both the analysis and control conditions. The children were taught by a paired-associate procedure to read four items that corresponded to the spoken syllables with which they had worked in the first phase. In our sample analysis condition, the items read would be $\mathrm{H}, \mathrm{EM}, \mathrm{HEM}$, and LIG. HEM is called the related item because it is related to the two smaller items in the set, $\mathrm{H}$ and EM. Its pronunciation can be deduced from those of the two small items. In other words, learning to say " $h$ " to $H$ and "em" to EM provides information, given phonemic analysis, that the proper response to HEM is "hem." LIG is called the unrelated item because it is not related to any other item in the set. Its pronunciation cannot be deduced from those of other items. In our sample control condition, in which the children repeated the spoken syllables "diz," "vok," "dok," and "viz," the items read would be D, IZ, DIZ (related item), and VOK (unrelated item).

Differences in performance on the related item and the unrelated item should reveal how children learn to read the items. If children fail to take advantage of the repeated spelling-sound correspondences, they should learn the related item no more easily than the unrelated item. That is, the fact that the pronunciation of the related item can be deduced from the pronunciations of the two small items should not be of help. Indeed, if children truly attempt to memorize the associations between whole printed words and their pronunciations (as suggested by Gough \& Hillinger, 1980), they may have more difficulty on the related item than on the unrelated item due to the similarity of the related item to the two smaller items. Studies of paired-associate learning (e.g., Horowitz, 1962) have documented that people perform poorly when similar-looking stimuli are paired with similar-sounding responses. Such effects have been found among children learning to read new words (Baron, 1977, pp. 211-213; McCutcheon \& McDowell, 1969; Otto \& Pizillo, 1970-1971; Samuels \& Jeffrey, 1966), which is consistent with the view that these children treat reading as a rote, pairedassociate task. In Baron's (1977) experiment, for example, 5-year-olds were taught to read pairs of words such as BOX and BUS by a method similar to that used here. They were then taught two related words, $\mathrm{OX}$ and US. The children, apparently confused by the similarity of the new words to the previously learned words, actually took more trials to learn the second pair of words than the first pair. Identical results emerged when the two-letter words were presented first. In the present study, if the children relied only on word-specific associations, they should have made more errors on the related item than on the unrelated item. This is the pattern we expected to observe in the reading task of the control conditionthe condition in which the children had not been taught to analyze the spoken syllables that corresponded to the written items of the reading task.

In contrast, if the children benefited from the relations between the spellings and the sounds of words, as we expected them to do in the analysis condition, they should have learned the related item more easily than the unrelated item. Transfer of spelling-sound correspondences learned from the two small items (e.g., H, EM) should have speeded the learning of the related item (HEM). Transfer should have been of no help with the unrelated item (LIG). Even though children in the analysis condition had been taught to segment the spoken syllable "lig" into "l" and "ig," they could not put this knowledge to use in the reading task because they had not been taught the written letters that corresponded to the constituent sounds. Hence, the children who took advantage of spelling-sound relations should have learned to read the related item more easily than the unrelated item. We expected that the children would show this pattern in the reading task of the analysis condition-the condition in which they had been taught to segment the spoken syllables that corresponded to the written items.

To summarize, the hypothesis that phonemicanalysis training promotes spelling-sound-rule use predicts an interaction between condition (analysis vs. control) and type of item (related vs. unrelated). In the control condition, the children should have performed more poorly on related items than on unrelated items; in the analysis condition, they should have performed better on related items than on unrelated items.

\section{Method}

Procedure. In the first phase of the analysis condition, the child was introduced to a puppet that "talked funny." The experimenter said each syllable herself (e.g., "hem") and then had the puppet say the initial consonant and the remaining portion (e.g., "h," "em"). When the initial consonant could not be pronounced in isolation, a schwa was added. (Pilot work had suggested that use of this neutral vowel caused children no added difficulty.) The child was asked to repeat what the puppet had said immediately after the puppet had said it. After the child had repeated each puppet form twice, the experimenter asked the child to work the puppet him- or herself. On each trial, the experimenter said all four syllables, in a random order each time, and the child attempted to say each syllable in "puppet talk." If the child made an error (here or in any other part of the procedure), the experimenter corrected the error by saying, "No, you said , but it should be
} 
tinued until the child had achieved 2 successive correct trials on all four syllables or until 10 test trials had been completed, whichever came first.

The procedure for the first phase of the control condition was the same, except that the puppet (a different puppet from the one used in the analysis condition) repeated each syllable whole. When the experimenter had said a syllable, the puppet, and the child, merely repeated it. The control condition occurred after the analysis condition on each test day. In this way, the number of test trials in the control condition could be matched to the number in the analysis condition. The children never produced errors in repeating the syllables.

A reading task constituted the second phase of each condition. Each trial involved all four printed items, for example H, EM, HEM, and LIG. Each item was printed on a separate card in large, uppercase letters. The experimenter first presented each card, gave the response, and asked the child to repeat it. (Note that the response for a single letter item, such as $\mathrm{H}$, was the letter's sound rather than its name.) This procedure continued for two trials. Then the child was asked to supply the responses. The four cards were presented in a random order on each trial, and errors were corrected. The procedure continued until the child had achieved 2 successive correct trials on all four items or until 10 test trials had been completed, whichever came first.

Stimuli. The stimuli were based on eight pairs of syllables: "hem," “lig"; "diz," “vok"; "med," “tap"; "pil,", "wur"; "bew," "zus"; "fat," "sun"'; "nip," "rox"; and "jaf," "cob", Each child used all eight pairs, a different one in each of the eight conditions (i.e., an analysis condition and a control condition on each of 4 days).

For the first phase of each condition, four syllables were useda base pair plus two additional syllables constructed by switching the initial consonants of a base pair. With the base pair "hem" and "lig," for instance, the four syllables would be "hem," "lig," "hig," and "lem." The analysis condition divided the syllables after the initial consonant (i.e., "hem" $\rightarrow$ " $h$," "em") rather than after the vowel (i.e., "hem"' $\rightarrow$ "he," "m"), since the former division appeared to be the more natural (MacKay, 1972; Treiman, in press). For the reading task, the first member of the base pair served as the related item, and the second served as the unrelated item. The related item was broken into its initial consonant and remainder to create two additional items (e.g., $\mathrm{H}$ and EM from HEM). Each base pair served in the analysis condition for approximately half the subjects and in the control condition for the other half. Also, the initial consonants within each base pair were switched for half the subjects. For these subjects, the items in the reading task would be L, EM, LEM, and HIG, for example. Each base pair was used approximately equally often on each of the 4 test days. Thus, differences between the analysis and control conditions or trends across test days should not have reflected the particular stimuli that were used.

Subjects. Eight preschool nonreaders served as the subjects. There were five girls and three boys; their mean age was 4 years 11 months (range $=3$ years 5 months to 6 years 0 months). The children attended local daycare centers. We selected children who could not read but who were willing and able to participate in our reading task. Teachers chose children whom they thought ready for the experiment, and these children were asked to read the items used in our reading tests. Any child who could read any of the items was disqualified, as was any child who performed errorlessly on the phonemic-analysis task. This was done to ensure that the subjects did not already know the skills we were trying to teach.

\section{Results and Discussion}

Table 1 shows the mean number of errors on related and unrelated items in the reading task of the two conditions. As predicted, there was a significant interaction between condition and item type $[F(1,7)$
Table 1

Mean Number of Errors on Related and Unrelated Items in Reading Task of Experiment 1

\begin{tabular}{lcc}
\hline & \multicolumn{2}{c}{ Item } \\
\cline { 2 - 3 } & Related & Unrelated \\
\hline Analysis Condition & 4.88 & 6.13 \\
Control Condition & 8.38 & 3.38 \\
\hline
\end{tabular}

$=9.29, \mathrm{p}<.025]$. Neither main effect was significant [for condition, $F(1,7)=.08$; for item type, $F(1,7)$ $=1.84$ ]. Examination of the pattern of results in each of the two conditions showed that, in the control condition, there were significantly more errors on related items than on unrelated items (Tukey's, $\mathrm{p}<$ .05 ). This pattern was shown by seven of the eight subjects. In the analysis condition, there was no statistically significant difference between errors on related items and errors on unrelated items. Six of the eight subjects, however, made fewer errors on related items than on unrelated items when in this condition.

Without phonemic-analysis training, then, children were actually hurt by the spelling-sound relations among the written items. They made more errors on the related item than on the unrelated item. This finding is consistent with several previous reports that children have more difficulty in learning to read similar-looking words than they do in learning to read dissimilar words (Baron, 1977; McCutcheon \& McDowell, 1969; Otto \& Pizillo, 1970-1971; Samuels \& Jeffrey, 1966). In the present study, the related item was similar to the two small items by virtue of the shared spelling-sound rules. Consequently, children made more errors on the related item than on the unrelated item in the control condition. The phonemicanalysis training offered in the analysis condition apparently allowed children to overcome the interference caused by repeated spelling-sound rules. Performance on the related items after analysis training was reliably better than performance on the same type of items when no such training had been given (Tukey's, $\mathrm{p}<.05$ ). Performance on the related items was not, however, significantly better than performance on the unrelated items in the analysis condition. The major result of phonemic-analysis training was the reduction of a negative effect rather than the production of a positive one. Nonetheless, the findings are consistent with the view that phonemicanalysis training enables children to benefit from spelling-sound rules to a greater degree than when they have had no such training.

An examination of the conditional probability of pronouncing a related item correctly, given correct pronunciation of the two smaller items on the same trial, provides additional evidence in favor of the hypothesis that phonemic-analysis training promotes spelling-sound-rule use. This conditional probability 
was .80 in the analysis condition and only .53 in the control condition, a significant difference $[t(7)=$ $1.97, p<.05$ ]. That the link between the related item and the small items was closer in the analysis condition than in the control condition suggests that children were more likely to deduce the related item on the basis of its constituents in the analysis condition.

The observed differences between the analysis and control conditions suggest that the phonemic-analysis training given here affected not the learning of all spelling-sound rules but the learning of just those rules involving the phonemes that had been used in training. Had the training effects been more general, and had they persisted from the analysis condition into the subsequent control condition on each test day, the subjects would have been helped in learning rules in the control condition as well. If such had been the case, we would not have observed differences in performance between the two conditions. Although we cannot rule out the possibility that some generalization from the analysis condition to the control condition did occur, it seems not to have been substantial. In particular, the interaction between condition and item type did not diminish over the 4 days of the experiment, as would have been expected if children had increasingly applied phonemicanalysis skills in the control condition as well as in the analysis condition. When the data for the third and fourth sessions of the experiment were analyzed separately, the interaction between condition and item type was still significant $[F(1,7)=5.85, \mathrm{p}<.05]$.

\section{EXPERIMENT 2}

Experiment 2 replicated the major features of Experiment 1. However, it differed from Experiment 1 in two primary ways. First, the initial phase of the analysis condition provided more extensive phonemicanalysis training than had been provided in Experiment 1 , including both segmentation and blending training. We predicted that this more extensive training would allow children to perform significantly better on related items than on unrelated items in the reading task of the analysis condition. Second, the reading task used in both conditions was modified. The children were first taught the two small items (e.g., H, EM) to criterion. Only then were the related item (HEM) and the unrelated item (LIG) introduced. This procedure ensured that the children were thoroughly familiar with the smaller items before they learned the larger items. As in Experiment 1, we predicted an interaction between training condition and item type such that children would perform better on the related item than on the unrelated item in the analysis condition but not in the control condition.

\section{Method}

Procedure. Each child participated in an analysis condition and in a control condition on each of 4 test days. In the first phase of the analysis condition, the child learned to segment and to blend four syllables (e.g., "hem," "lig," "hig," "lem"). The segmentation training was given first; it followed the same procedure that had been used in Experiment 1. Training in blending was given next. Here, the puppet first said each syllable in segmented form (e.g., "h," "em"), and the child attempted to say the whole syllable ("hem"). Two demonstration trials were given. Test trials continued until the child had achieved a criterion of 2 successive correct trials on all four items or until 10 trials had been completed.

In the first phase of the control condition, the child (and the puppet) merely repeated spoken items. The procedure was similar to that of Experiment 1, but eight, rather than four, items (e.g., "“diz," “vok,"” "dok," "viz,"” “d," “v," “iz," “ok") were repeated. This procedure ensured that the child was exposed to the small units as well as to the longer syllables.

The second phase of each condition was a reading task. It began with two demonstration trials on the two small items (e.g., H, EM). Test trials on these items continued until the child had reached a criterion of 3 successive correct trials on both items or had reached a maximum of 10 test trials. Then the two three-letter items-the related item (e.g., HEM) and the unrelated item (e.g., LIG)-were introduced. On the first trial, the experimenter asked the child to try to pronounce the items. She told the child that, in trying to read the new items, he or she should think of the items that had been learned already. Only after the child had had a chance to respond did the experimenter provide the pronunciations. Test trials continued until the child had achieved 3 successive correct trials on both items or until 10 trials had been completed.

Unlike in Experiment 1, in which the analysis condition occurred first on all test days, the analysis condition of Experiment 2 occurred first on 2 randomly chosen test days for each child and the control condition occurred first on the other 2 test days. A fixed number of repetition trials-two demonstration trials and two test trials-was given in the control condition. This change was made to rule out a possible alternative interpretation of the interaction obtained in Experiment 1. This interpretation held that the children in Experiment 1 were tired by the time they had reached the reading task in the control condition and, because transfer of spelling-sound rules requires mental effort, did not use these rules to the extent that they otherwise would have.

Stimuli. The stimuli and counterbalancing in Experiment 2 were the same as in Experiment 1.

Subjects. The subjects were 20 children attending local kindergartens. There were 9 girls and 11 boys; their mean age was 5 years 9 months (range $=5$ years 3 months to 6 years 3 months). Potential subjects, randomly chosen from children in participating classrooms, were given both a reading pretest and a phonemic-analysis pretest. In the reading pretest, the subjects were asked to read the three-letter items used in the experiment. Only one potential subject could read any of the items, and this subject was disqualified. In the phonemic-analysis pretest, the subjects were shown how to analyze two spoken syllables into initial consonants and remainders. They were then asked to analyze four new syllables in the same way. The subjects who performed correctly on any of the four test syllables did not participate in the experiment, since they already possessed some of the phonemic-analysis skills we were trying to teach. Six potential subjects were disqualified for this reason. An additional two subjects were dropped from the experiment because they did not wish to continue and did not pay attention.

\section{Results}

The top portion of Table 2 shows the reading-task results averaged over all 20 subjects. An analysis of 
variance on these data showed that the interaction between condition and item type was significant $[F(1,19)=6.76, p<.02]$, as predicted. Neither the main effect of condition nor that of item type was significant [for condition, $F(1,19)=.39$; for item type, $F(1,19)=.50$ ]. In contrast with Experiment 1 , no significant difference was found between relateditem errors and unrelated-item errors in the control condition. In the analysis condition, however, the children made reliably fewer errors on related items than on unrelated items (Tukey's, $p<.05$ ). Thus, the subjects did better on the related items than on the unrelated items in the analysis condition but not in the control condition. Only in the analysis condition were the subjects able to derive significant positive benefit from the relation between the two small items and the related item.

Additional post hoc tests showed that the children made significantly more errors on unrelated items in the analysis condition than in the control condition (Tukey's, $\mathrm{p}<.01$ ). (Errors on related items did not differ significantly between the two conditions.) Although not specifically predicted, this result is consistent with the view that phonemic-analysis training promotes use of spelling-sound rules in reading and discourages use of word-specific associations. Consequently, such training may hinder performance on the unrelated item, for which only specific associations can be used.

Although the above results support our hypothesis, they are not identical to those of Experiment 1, in which the tendency to use word-specific associations seemed stronger. This difference may be due to differences in the subject populations. To assess this possibility, the data for Experiment 2 were analyzed separately for those subjects who were less skilled in phonemic analysis (defined as those whose errors in segmentation and blending in the first 2 days of the experiment exceeded the median number) and those who were more skilled. These results are shown in Table 2 . The subjects who were less skilled

Table 2

Mean Number of Errors on Related and Unrelated Items in Reading Task of Experiment 2

\begin{tabular}{ccc} 
& \multicolumn{2}{c}{ Item } \\
\cline { 2 - 3 } & Related & Unrelated \\
\hline & All Subjects & \\
Analysis Condition & 9.20 & 10.60 \\
Control Condition & 9.60 & 8.90 \\
Subjects Less Skilled in Phonemic Analysis \\
Analysis Condition & 10.40 & 12.70 \\
Control Condition & 11.80 & 10.10 \\
Subjects More Skilled in Phonemic Analysis \\
Analysis Condition & 8.00 & 8.50 \\
Control Condition & 7.40 & 7.70 \\
\hline
\end{tabular}

in phonemic analysis showed a highly significant interaction between condition and item type $[F(1,9)=$ $13.09, p<.006]$. In the control condition, these children made more errors on related items than on unrelated items (Tukey's, $\mathrm{p}=.06$ ); in the analysis condition, they made fewer errors on related items than on unrelated items (Tukey's, $p<.05$ ). That is, these subjects showed both predicted effects: interference due to repeated spelling-sound rules in the absence of phonemic-analysis training, and facilitation after phonemic-analysis training. The children who were more skilled in phonemic analysis at the outset (i.e., those whose errors in segmentation and blending in the first 2 days of the experiment were below the median) did not show a significant interaction between condition and item type $[F(1,9)=$ $.05)$. Although the main effect of item type also was nonsignificant for these children, they did tend to make fewer errors on related items than on unrelated items in both conditions. (The results are similar when groups are defined on the basis of segmentation and blending errors in all 4 days of the experiment.)

In contrast with Experiment 1, the interaction between condition and item type declined over the 4 days of the experiment. It was seen when the data for the first 2 days of the experiment were analyzed $[F(1,19)=4.27, \mathrm{p}<.055]$, but not when the data for the last 2 days were analyzed $[F(1,19)=.29]$. These results suggest that, as the Experiment 2 subjects became more skilled in phonemic analysis, they increasingly used these skills in the control-condition reading task as well as in the analysis-condition reading task.

\section{GENERAL DISCUSSION}

The results of Experiments 1 and 2 concur in demonstrating a significant interaction between condition and item type in the reading task. In the control condition, in which children were exposed to certain spoken syllables but were not taught to analyze them, they failed to benefit from spelling-sound rules when they learned to read the corresponding written items. That the pronunciation of the related item could be deduced from the pronunciations of the two small items did not help the children in this condition. Indeed, the Experiment 1 subjects made significantly more errors on the related item than on the item whose pronunciation could not be so deduced. In contrast, in the analysis condition, the subjects tended to make fewer errors on the related item than on the related item. This trend was not significant in Experiment 1, but was significant in Experiment 2. Thus, explicit instruction in analysis of the spoken syllables permitted the subjects in both experiments to take advantage of the spelling-sound relations to a 
greater degree than they were able to do without such instruction. This result supports the hypothesis of a direct link from phonemic analysis to ability to benefit from spelling-sound correspondences.

It is important to note that phonemic-analysis training did not reduce the total number of errors in the reading task in either experiment. No main effects of condition were found. However, training did alter the pattern of performance on related and unrelated items. We have suggested that better performance on related items than on unrelated items shows that children derive benefit from spellingsound relationships. Thus, the interaction between condition and item type indicates that children gain more benefit from spelling-sound rules with phonemicanalysis training than without it.

Although the subjects in both experiments performed better on related items relative to unrelated items in the analysis condition than in the control condition, several differences in their patterns of results merit discussion. One difference is that the Experiment 1 subjects were actually hurt by spellingsound relations in the absence of phonemic-analysis instruction, whereas the Experiment 2 subjects, as a group, were not. Several factors may have contributed to this difference, but we suggest that the Experiment 1 subjects-younger, less educated, and presumably poorer in phonemic analysis than the Experiment 2 subjects-were more prone to treat the reading task in a rote, paired-associate fashion. (For a similar view, see Gough \& Hillinger, 1980). Consequently, as discussed earlier, they were hurt by the similarity of the related item to the two small items. Consistent with this analysis is the finding that those subjects in Experiment 2 who were below the median in phonemic-analysis skill made-as did the Experiment 1 subjects-more errors on related items than on unrelated items in the control condition. A second difference between the experiments lies in the pattern of results in the analysis condition. The Experiment 1 subjects did not perform significantly better on related items than on unrelated items after phonemicanalysis training; the Experiment 2 subjects did make fewer errors on related items than on unrelated items in the analysis condition. The difference in results may be due to the more intensive phonemic-analysis instruction, including both segmentation and blending training, provided in Experiment 2. Indeed, it has been suggested that blending plays a more important role than does segmentation in promoting reading acquisition (Perfetti, Beck, \& Hughes, Note 3). A final difference between the results of the two experiments is that in Experiment 1 the interaction did not appear to decline over the 4 test days, whereas in Experiment 2 it did decline. This difference may be due to differences in the subject populations: The older and more experienced Experiment 2 subjects may have been more able to transfer skills learned in the analysis condition to the control condition.
Task differences may also have played a role. The phonemic-analysis training provided in Experiment 2, since it was more intensive, may have been more likely to generalize. Further research is needed to evaluate these suggestions about the role of subject and task variables.

The present results support the theoretical view, discussed in the introduction, that phonemic awareness facilitates the learning of spelling-sound rules. They suggest that the correlations previously observed between phonemic-analysis skill and spellingsound-rule use (Baron \& Treiman, 1980; Treiman \& Baron, 1981) reflect, at least in part, a causal link from phonemic analysis to spelling-sound-rule learning. Likewise, our results suggest that previous findings of improved reading skill following phonemicanalysis instruction (Rosner, Note 1; McNeil \& Coleman, Note 2) arose because this instruction helped children to learn spelling-sound relations. The link between phonemic analysis and spelling-soundrule use presumably exists because children who can explicitly analyze spoken words into their phonemic components are able to learn the correspondences between phoneme units and letter units. Since ability to use these correspondences appears to be an important part of reading success (e.g., Firth, 1972), our results suggest that phonemic-analysis training can promote reading skill.

The present results also have implications for educational practice. If the goal of reading instruction were simply to teach children a small set of words, rote word-specific associations might be satisfactory. In this case, our results would lead us to recommend that dissimilar words be taught together. Pairedassociate learning, it appears, is most successful under these circumstances. However, if the goal of reading instruction is (as we believe) to allow children to read any word in their spoken vocabulary, rote learning will not suffice. Children must be able to decipher new printed words on the basis of previously learned words. They must be able to transfer their knowledge of spelling-sound rules to related words. Certain methods of reading instruction, such as the "linguistic" methods of Bloomfield (1942) and others, assume that, if related words (e.g., CAT, BAT, and HAT) are taught together, children will induce spelling-sound rules-in this case the rule that AT corresponds to "at." Our results suggest that many children will, instead, be hurt by the similarity among items that necessarily arises when spellingsound rules are repeated. They will make more errors on words that embody the rule than on words that do not. Our results also show that phonemic-analysis training with the corresponding spoken words can overcome such negative effects and can, in some cases, produce a positive benefit. Indeed, several successful reading programs (e.g., Wallach \& Wallach, 1979; Williams, 1980) include phonemic-analysis training as an important component. Researchers 
(e.g., Lewkowicz, 1980) have begun to study the ways in which such training can most effectively be done in an educational setting.

\section{REFERENCE NOTES}

1. Rosner, J. Phonic analysis training and beginning reading skills (Publication 1971/19). Pittsburgh: Learning Research and Developmental Center, 1971.

2. McNeil, J. D., \& Coleman, J. C. Auditory discrimination training in the development of word analysis skills (Final Report, U.S. Office of Education Project No. 5-0503). Los Angeles: University of California, 1967.

3. Perfetti, C. A., Beck, I. L., \& Hughes, C. Phonemic knowledge and learning to read. Paper presented at the meeting of the Society for Research in Child Development, Boston, April 1981.

\section{REFERENCES}

BARon, J. Mechanisms for pronouncing printed words: Use and acquisition. In D. LaBerge \& S. J. Samuels (Eds.), Basic processes in reading: Perception and comprehension. Hillsdale, N.J: Erlbaum, 1977.

Baron, J. Orthographic and word-specific mechanisms in children's reading of words. Child Development, 1979, 50, 60-72.

BAron, J., \& HoDGE, J. Using spelling-sound correspondences without trying to learn them. Visible Language, 1978, 12, 55-70.

Baron, J., \& Treiman, $R$. Use of orthography in reading and learning to read. In J. F. Kavanagh \& R. L. Venezky (Eds.), Orthography, reading, and dyslexia. Baltimore: University Park Press, 1980.

Bloomfield, L. Linguistics and reading. Elementary English Review, 1942, 19(1), 125-130; 183-186.

Boder, E. Developmental dyslexia: Prevailing diagnostic concepts and a new diagnostic approach. In H. R. Myklebust (Ed.), Progress in learning disabilities (Vol. 2). New York: Grune \& Stratton, 1971.

BoDer, E. Developmental dyslexia: A diagnostic approach based on three atypical reading-spelling patterns. Developmental Medicine and Child Neurology, 1973, 15, 663-687.

Brooks, L. R. Non-analytic correspondences and pattern in word pronunciation. In J. Requin (Ed.), Attention and performance VII. Hillsdale, N.J: Erlbaum, 1978.

Calfee, R. C., Chapman, R. S., \& Venezky, R. How a child needs to think to learn to read. In L. W. Gregg (Ed.), Cognition in learning and memory. New York: Wiley, 1972.

Calpee, R. C., Lindamood, P., \& Lindamood, C. Acousticphonetic skills and reading-Kindergarten through twelfth grade. Journal of Educational Psychology, 1973, 64, 293-298.

Ehri, L. C., \& WILCE, L. S. The mnemonic value of orthography among beginning readers. Journal of Educational Psychology, $1979,71,26-40$.

ELkonin, D. B. USSR. In J. Downing (Ed.), Comparative reading. New York: Macmillan, 1973.

Finth, I. Components of reading disability. Unpublished doctoral dissertation, University of New South Wales, 1972.

Fox, B., \& Routh, D. K. Analyzing spoken language into words, syllables and phonemes: A developmental study. Journal of Psycholinguistic Research, 1975, 4, 331-342.

Gle itman, L. R., \& Rozin, P. The structure and acquisition of reading I: Relations between orthographies and the structure of language. In A. S. Reber \& D. L. Scarborough (Eds.), Toward a psychology of reading: The proceedings of the CUNY conferences. Hillsdale, N.J: Erlbaum, 1977.

GolinkofF, R. M. Phonemic awareness skills and reading achievement. In F. Murphy \& J. Pikulski (Eds.), The acquisition of reading. Baltimore: University Park Press, 1978.

Gough, P. B., \& Hillinger, M. L. Learning to read: An unnatural act. Bulletin of the Orton Society, 1980, 30, 179-196.

Hardy, M., Stennett, R. G., \& Smythe, P. C. Auditory segmentation and auditory blending in relation to beginning reading. Alberta Journal of Educational Research, 1973, 19, 144-158.
Helfgott, J. A. Phonemic segmentation and blending skills of kindergarten children: Implications for beginning reading acquisition. Contemporary Educational Psychology, 1976, 1, 157-169.

Horowitz, L. M. Associative matching and intralist similarity. Psychological Reports, 1962, 10, 751-757.

Jusczyk, P. W. Rhymes and reasons: Some aspects of the child's appreciation of poetic form. Developmental Psychology, 1977, $13,599-607$

Lew Kowicz, N. K. Phonemic awareness training: What to teach and how to teach it. Journal of Educational Psychology, 1980, 72, 686-700.

Liberman, I., Liberman, A. M., Mattingly, I., \& ShankWEILER, D. Orthography and the beginning reader. In J. F. Kavanagh \& R. L. Venezky (Eds.), Orthography, reading, and dyslexia. Baltimore: University Park Press, 1980.

Liberman, I. Y., Shankweiler, D., Fischer, F. W., \& CARTER, B. Explicit syllable and phoneme segmentation in the young child. Journal of Experimental Child Psychology, 1974, 18, 201-212.

McKAY, D. G. The structure of words and syllables: Evidence from errors in speech. Cognitive Psychology, 1972, 3, 210-227.

McCutcheon, B. A., \& McDowell, E. E. Intralist similarity and acquisition and generalization of word recognition. The Reading Teacher, 1969, 23(2), 103-107; 115.

Morais, J., Cary, L., Alegria, J., \& Bertellon, P. Does awareness of speech as a sequence of phones arise spontaneously? Cognition, 1979, 7, 323-331.

Otтo, W., \& Pizillo, C. Effect of intralist similarity on kindergarten pupils' rate of word acquisition and transfer. Journal of Reading Behavior, 1970-1971, 3, 14-19.

Rosner, J., \& Simon, D. The Auditory Analysis Test: An initial report. Journal of Learning Disabilities, 1971, 4, 384-392.

Rozin, P., \& Gleitman, L. R. The structure and acquisition of reading II: The reading process and the acquisition of the alphabetic principle. In A. S. Reber \& D. L. Scarborough (Eds.), Toward a psychology of reading: The proceedings of the CUNY conferences. Hillsdale, N.J: Erlbaum, 1977.

SAmuel.s, S. J., \& JefFreY, W. E. Discriminability of words and letter cues used in learning to read. Journal of Educational Psychology, 1966, 57, 337-340.

SNowling, M. J. The development of grapheme-phoneme correspondence in normal and dyslexic readers. Journal of Experimental Child Psychology, 1980, 29, 294-305.

Treiman, R. The structure of spoken syllables: Evidence from novel word games. Cognition, in press.

Treiman, R., \& Baron, J. Segmental analysis ability: Development and relation to reading ability. In G. E. MacKinnon \& T. G. Waller (Eds.), Reading research: Advances in theory and practice (Vol. 3). New York: Academic Press, 1981.

Wallach, M. A., \& Wallach, L. Helping disadvantaged children learn to read by teaching them phoneme identification skills. In L. B. Resnick \& P. A. Weaver (Eds.), Theory and practice of early reading (Vol. 3). Hillsdale, N.J: Erlbaum, 1979.

Williams, J. P. Teaching decoding with an emphasis on phoneme analysis and phoneme blending. Journal of Educational Psychology, 1980, 72, 1-15.

\section{NOTES}

1. Although there are different ways of analyzing speech into phonemes, different analyses almost always agree in relevant respects for the stimuli we use. Thus, we put aside questions about which analysis corresponds most closely to spelling or to children's representations of speech.

2. Several mechanisms for transfer are possible. For example, transfer may occur by deducing the pronunciation of one item from the pronunciations of others or by analogy (Baron, 1979; Baron \& Hodge, 1978; Brooks, 1978).

(Manuscript received November 17, 1982; revision accepted for publication April 4, 1983.) 